\title{
The Research of Agricultural Landscape Evolution in Mountain Area of Southern Jinan Based on Stakeholder Theory
}

\author{
Da-liang Liu" ${ }^{1, ~ *, ~ H u a-b i n ~ X i a o ², ~ G u i-j u ~ L v ~}{ }^{3}$ \\ ${ }^{1}$ College of Art, Shandong Jianzhu University, Jinan, China \\ ${ }^{2}$ School of Architecture and Urban Planning, Shandong Jianzhu University, Jinan, China \\ ${ }^{3}$ School of Architecture and Landscape Design, Shandong University of Art and Design, Jinan, China \\ Email address: \\ 893983843 aqq.com (Da-liang Liu) \\ ${ }^{*}$ Corresponding author
}

To cite this article:

Da-liang Liu, Hua-bin Xiao, Gui-ju Lv. The Research of Agricultural Landscape Evolution in Mountain Area of Southern Jinan Based on Stakeholder Theory. International Journal of Environmental Protection and Policy. Vol. 6, No. 1, 2018, pp. 19-25. doi: 10.11648/j.ijepp.20180601.14

Received: January 18, 2018; Accepted: March 19, 2018; Published: May 14, 2018

\begin{abstract}
In the course of social evolution, urban fringe districts have been attracting more and more attention and the management and control of ecological protection have been strengthened as well. Meanwhile, the Party Central Committee also puts emphasis on the importance of agricultural landscape. Urban fringe districts represented by mountain area of southern Jinan are under control of the government and restricted in a settled ecological redline. Therefore, it is difficult for agricultural landscape to exert its economic function in tourism and leisure. Under this circumstance, the government's demand for preservation and the people's demand for development have created a conflict of land use. On the basis of stakeholder theory, this paper takes a further step to analyze the multivariate game among local government, village collectives and villagers. The demand and willing of key stakeholders should be reasonably expressed to integrate agricultural development with tertiary industry, guarantee the proper layout of agricultural landscape in space during the course of land evolution, thus its comprehensive value functions can be accomplished.
\end{abstract}

Keywords: Agricultural Landscape, Stakeholder Theory, Conflict of Land Use

\section{Introduction}

The development of cities in China is accompanied by the high intensity exploitation of resources. With the increasing expansion of cities, the land resources in urban fringe districts have provoked competition among multivariate stakeholders. As villages who locate in cities' marginal areas, the major way to develop their economy depends on primary industry. However, when the resource is under systematic restriction, the conflict of land use will emerge. To deal with the conflict between human and land, stakeholder theory can be adopted to come up with a plan to handle their relationships through analyzing the game among stakeholders.

The natural and agricultural ecosystem of urban fringe districts is a necessary basis for ecological safety and sustainable development of cities [1-3]. The rapid urbanization has caused a series of problems in urban environment and ecosystem. Faced with these problems, the government has begun to strengthen the management and control of natural resources and ecosystems to protect ecological benefits. As vulnerable groups, the local villagers' interests and demands of economic development are often neglected. Owing to the villagers' dependence on land resources for their livelihood, the government's strict control can easily give rise to conflicts with villagers. The most ideal mode for the planning of urban fringe districts is to coordinate the top-down policy making with the the bottom-up development demands, and make different stakeholders in a society to reach a consensus. Nevertheless, the actual process of planning is long and difficult, there must be fierce competition among different stakeholders. The agricultural 
development in urban fringe districts is under double restriction: land mechanism and ecological protection, so the protection and development of agricultural landscape should be paid attention to.

In 2013, Document NO.1 of the Central Government first put forward the concept of "family farm". In 2006, it pointed out the development of leisure agriculture and farmhouse resorts. In 2007, the concept of "pastoral complex" has been come up with. These agricultural development strategies all combined primary industry with tertiary industry, which not only pointed out the direction of development, but became a protection of agricultural landscape. It is no doubt that in the conversion process from land resources to economic profits, relying solely on traditional agriculture for the villagers to bring economic benefits will no longer meet their needs. Villagers in urban fringe districts hoped to transfer part of the cultivated land into construction land to promote regional development. However, to protect the ecological environment, the government restricted it into a protective cage, even prohibited the any other use of cultivated land. The government put the overall protection of the city into priority, regardless of the villagers' demand to replan the land use, neglecting the local economic development. In this conflict, the local government and the villagers were both not aware of the full value of the agricultural landscape. One side hopes to benefit ecological development through preserving the cultivated land; the other side hopes to develop economy through agricultural tourism. We may draw the conclusion that China still stays in the level of expression through production factors in landscape, while the agricultural landscape should have been the integration of value in production, landscape, economy, society, culture, ecology and leisure etc [4-5].

\section{The Overview of Agricultural Landscape Protection and Development of the Research Area}

In the agricultural landscapes in mountain area of southern Jinan (Figure 1), forest landscape is the majority, cultivated land and garden land are followed by. Forest mostly distributes over mountains, while garden land distributing in half way up and at the foot of the mountains and cultivated land only at the foot of the mountains. The special mountain terrain has formed the distribution characteristics of the agricultural landscape in this area. Therefore, the southern mountain area has become a source area of Jinan's springs, and has always been standing on the important ecological status.

The problem of illegal buildings and environmental vulnerability still exist since the propose of south control policy in 2003. The government not only did not do a good job in the control work, but the general life quality of southern mountain villagers have not been improved. To cope with this situation, the government of Jinan established a management committee in southern mountain areas. According to the urban comprehensive planning of Jinan (2011-2020), its central city will expand toward south, while this expansion belongs to a non-construction land planning, which shows the government's a strong determination to control the southern mountain area. In this planing, the basic cultivated land and drinking water source area have been classified into construction-forbidden district, common cultivated land and forest areas have also become construction-limited district, which draws a strict limitation in basic ecological line. Meanwhile, the government shows an attitude that when checking and evaluating three towns of Xiying, Zhonggong and Liubu in southern mountain area, economic indicators like GDP will no longer be considered into evaluation. Instead, green protection and development have attracted more and more attention. But in the implementation of the policy, there are conflicts between protection and development. In the face of this situation, the government will mainly protect the southern mountain area, putting emphasis on the environmental protection and ecological restoration of this area.

For over ten years, in the process of conflicts coordination between protection and development, the government has intensified the protection of southern mountain area and has formed a system, but its development has always made the local villagers miserable. Until 2013, the number of industry projects in core area of southern mountain, whose output value in revenue is more than 5000 yuan, has come up to 158 , and only 45 that are more than 100,000 yuan. Besides, the income of the farmer mainly depends on working in the city, accounting for around $60 \%$ of the general income, with agricultural production income for about $30 \%$ and farmhouse resorts for about $10 \%$. In recent years, the policy of south control has not been slightly loosed, making villagers in southern mountain area cannot find a supportive industry to increase their income [6-8]. The ravines and rocks that can hardly be reclaimed are classified as common cultivated land; The construction land cannot be found when trying to develop modern agriculture and conduct deep processing of agricultural products; It is difficult to apply for the construction land of tourism project. Under the circumstance of protection as priority, the willing for development of villagers in southern mountain area will be stronger and stronger. At the same time, there will be more hardships, which will definitely enhance the conflict between local villagers and local cadres at the grassroot level, even the the upper level of government.

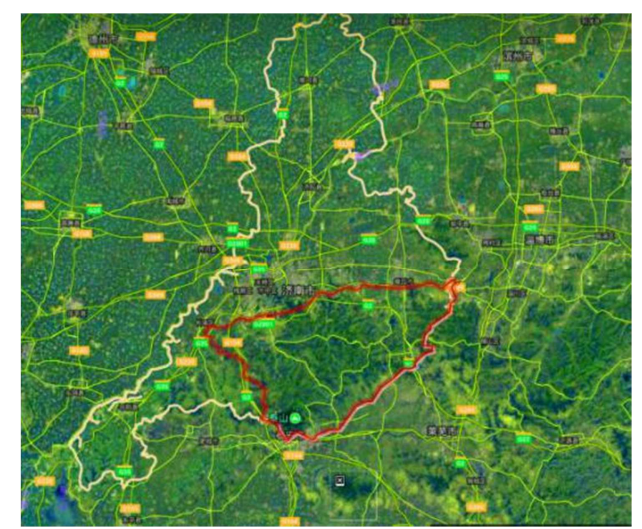

Figure 1. The geographical map of southern mountain area. 


\section{The Pattern Evolution of Agricultural Landscape of the Research Area}

The evolution of land use is a long-term result of the interaction between human and land, reflecting the dynamic relationship of feedback from human and the surface system. The pattern evolution of agricultural landscape demonstrates
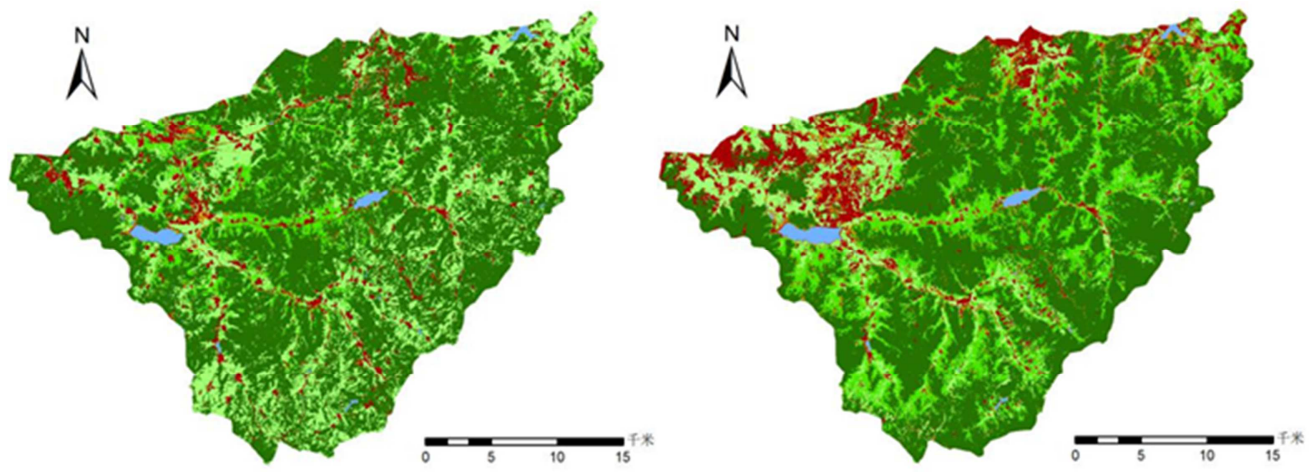

In 2001

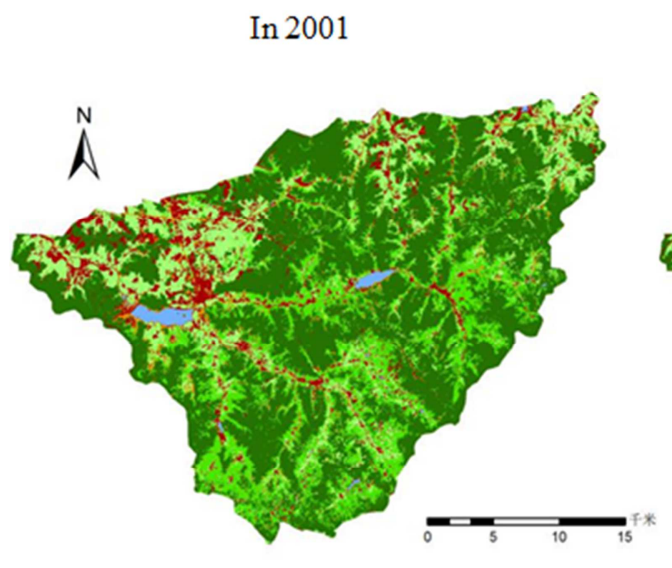

In 2013

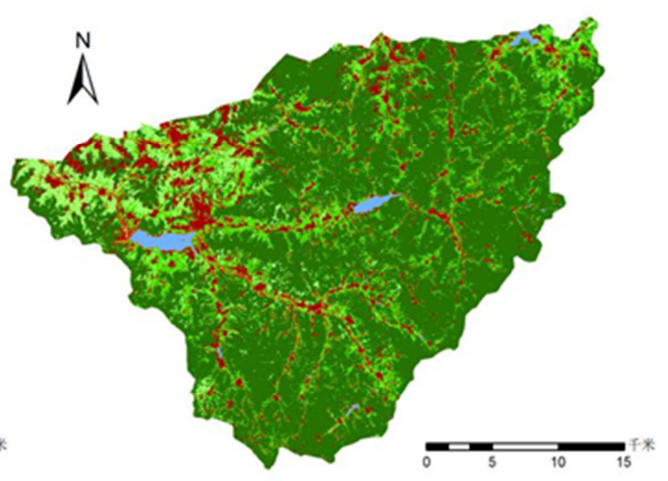

In 2016 the degree of human's influence, as well as the interactions between society, politics and economy. As the network space formed by woodland, cultivated land, garden field, water and other variety of landscapes, its pattern is the result of long-term or cyclical operations of the land, and it is also changing with land-use change [9-10].

Woodland $\square$ Cultivated Land $\square$ Traffic Land
Garden Land $\square$ Water
$\square \quad$ Construction Land for Cities and Towns

Figure 2. Southern mountain area at different phases explained by envi.

According to the Classification of Land Use GB / 21010-2007, the study area is divided into six categories: cultivated land, garden land, forest land, water area, traffic land and urban construction land. The agricultural landscapes studied in this paper are cultivated land, forest land and garden land.

Through the interpretation of the southern mountain area by envi from 2001 to 2016, it was found that the forest land in these area decreased from 2001 to 2006 , and at the same time, there was also a significant increase in construction land, a small growth of garden land and a relatively reduction of cultivated land. From 2006 to 2013, there was no obvious change in all types of agricultural land. From 2013 to 2016, the woodland in the southern mountain area increased significantly, the cultivated land was further reduced, and some of the garden land changed to the forest land. Overall, from 2001 to 2016, the forest land in southern mountain area had been significantly expanding, which is driven by the implementation of various "green construction" measures, while the cultivated land in southern mountain area had been reduced and the garden land had increased slightly. In addition, the construction land had been growing for the past two decades whose distribution was relatively fragmented. The reasons of this phenomenon can be explained that the local villagers treated the plant of fruit trees as the main source of income in their life, as well as the continuous building of farmhouses and rural villas in recent years (Figure 2and Figure 3). 


\section{Characteristics of Agricultural Landscape Conflict of the Research Area}

The southern part of the mountain area is large and has a different variety of terrains, and the government implemented different policies on benefiting people. These have resulted in the prominent land use conflict and local conflict in the southern mountain area. Whereas because of the different development extent of the villages, the reasons for the conflict are not the same. In the southern mountain area, the whole level of development is generally poor. Therefore, I take Shiling Village as an example to analyze conflict stage.

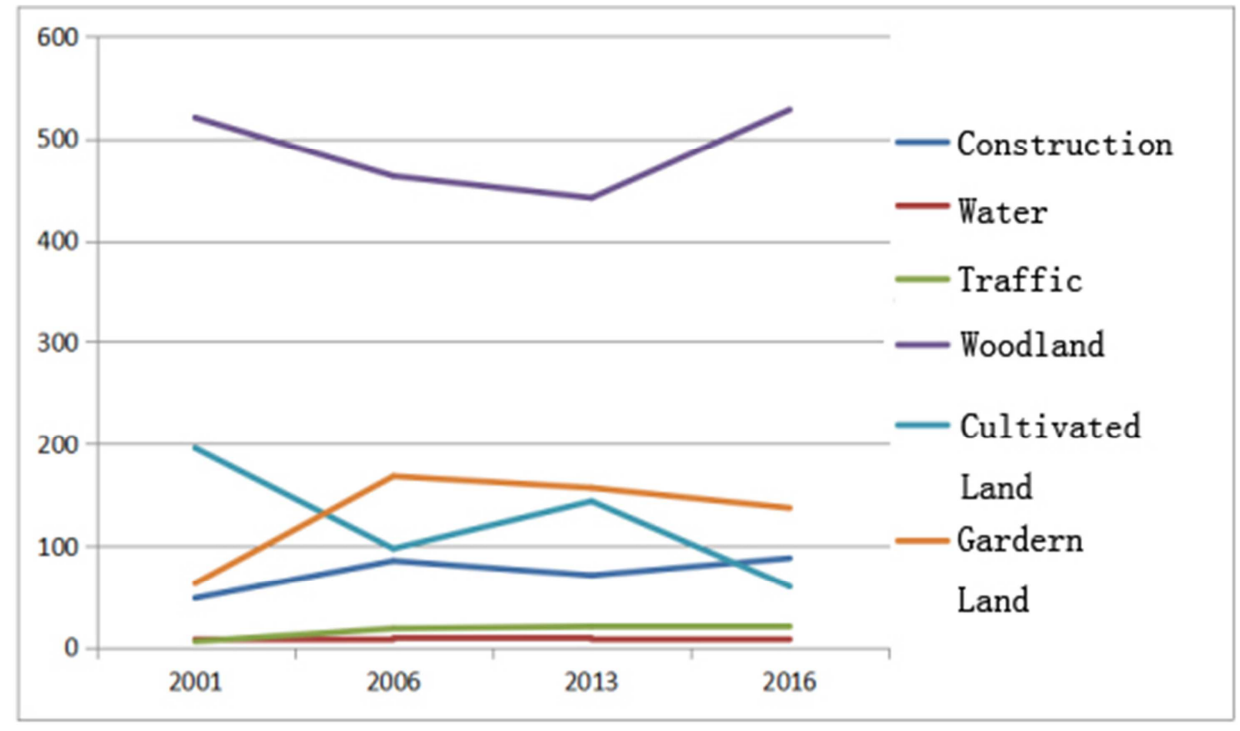

Figure 3. Variation trend of different types land use from 2001-2016.

Since the founding of the People's Republic of China, there are six relatively important time nodes that deserve to be noticed, (1) In 1982, the policy of fixing of farm output quotas for each household was put into practice, enabling local villagers to have an independent right to choose what to plant; (2) In 1998, the Ministry of Land and Resources was set up and classified the newly revised Land Management Law as the basic state policy. (3) In 2001, the southern mountain area was established as an important city reserve for ecological function. (4) In 2006, the Eleventh Five-Year Plan came up with eco-tourism and established a Management Office for the southern mountain area. (5) In 2011, the planning of ecological protection and economic development in southern mountain area of Licheng District was unveiled. (6) In 2016, the Southern Mountain Management Committee was formally established to manage this area.

\subsection{Conflict Potential Stage (1978-1982)}

In 1978, the policy of reform and opening up improved the general economic development of our country. Furthermore, the government's decentralization and the increase of market vitality stimulated the enthusiasm of farmers to increase production. In 1982, the policy of fixing of farm output quotas for each household was formally carried out in the whole country, thus the villagers had the right to independently use their land, and the enthusiasm of production was further improved. During this period, the level of national economy was ready to develop, yet the overall living standard of people was relatively low. The income of the villagers in the southern mountain area still depended on agricultural production. There was not any sign of conflict.

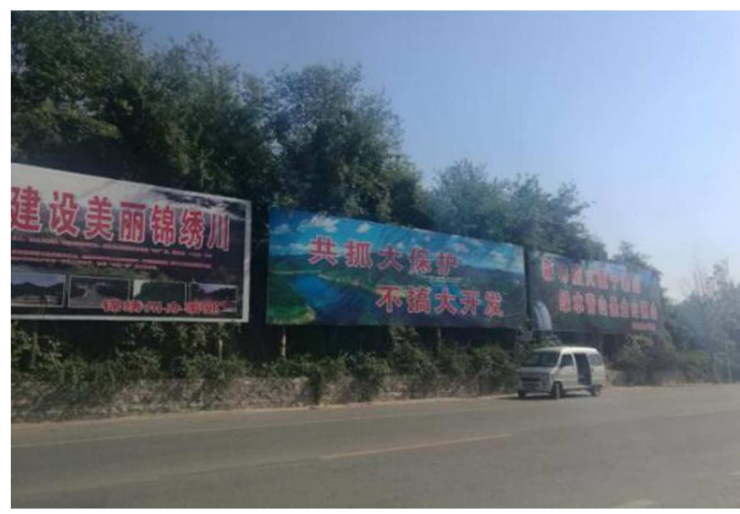

Figure 4. The roadside publicity board in southern mountain area.

\subsection{Conflict Intention Stage (1982-2001)}

In 1985, the reduction of national arable land reached more than 1 million hectares, and it was the year in which cultivated land suffered the largest reduction since the founding of People's Republic of China.

Since then the number of cultivated land continued to decrease. At the same time, the national people's awareness of protecting the arable land was awaken. In 1998, the Ministry of Land and Resources was set up to formally put the protection of cultivated land into agenda. The government of Jinan also made the southern mountain area as an important ecological function reserve in 2001 and set up the relevant protection regulations. 


\subsection{Conflict Practice Stage (2001-2011)}

The government's growing emphasis on the ecological environment has made the southern mountain area under continuous control since 2001. In 2002, the southern mountain area was further established as provincial reserve of ecological functions by the Shandong provincial government. In 2003, the the newly unveiled development strategy by the municipal government of Jinan proposed the policy of "south control", specifying planning objective of the southern mountain area, that is protection. During this period, the government strictly control the development of industrial enterprises, put the ecological interests in the first place, which almost stagnated the economy of the entire southern mountain area. Although the tourism industry has developed, the local farmers did not receive the benefits. As a result, the farmhouse resorts and picking industry appeared. Farmhouse resorts brought some income for the farmers, but they also undermined the local ecological environment. The picking garden organized by the village collective was difficult to maintain resulted in the lack of finance. The protection of the local government made it difficult for the villagers to satisfy their economic needs, hence the conflict of interest demand between people and the government ensued.

\subsection{Conflict Structure Stage (2011-Present)}

In 2011, the local government made a decision to raise $60 \%$ of the forest coverage in the southern mountain area. In August 2016, the Southern Mountain Management Committee was formally established, and pointed out that the standard of check and evaluation should be replaced by "green construction", instead of economic indicators such as GDP. Since then, the management committee has been carrying out the management approach of "expansion" and "demolition" to pull down a large quantity of the illegal construction in mountain area, while strictly defined the use of farmland and other types of land (Figure 4). The development of the villagers was further limited, and the development demands of village collective were difficult to achieve, too. Although the villagers supported the policy for the protection of local ecological environment, they thought that the government did not take the local situation into full consideration with the continuous strengthening of management and control. It was impossible to reach a consensus between people and the government.

\section{The Multivariate Game Among Stakeholders}

According to the definition of Freeman, stakeholder refers to any group or individual that can influence the realization of an organization's goal or can be affected by it (Freeman 1984). In the process of gaming between protection and development in mountain area of southern Jinan, the central government, as the defender of public interests, makes the development strategies, laws and regulations. As an implementer, the local government adjusts and carries out the policy complying with the local situation to manage and control. Meanwhile, it also faces the double pressures on the development of regional tourism resources and ecological protection. Because of the far distance from southern part of the mountain area to the city and the inconvenience of traffic network, its economy has been dominated by the primary industry for a long time and has developed at a slow pace. In recent years, under the influence of the "south control" policy, it is hard to introduce large-scale industries. In this case, a majority of villages in the southern mountain area are weak in economic development. As the owner of the southern mountain area, local villagers and village collectives' basic interests have not been taken seriously.

From a poverty-stricken village to today's ecological rich village, Aijia Village in southern mountain area has become a successful development case. Although limited by the industrial development, Aijia Village has blazed its own way in agricultural development. For example, cherry picking industry has increased the income of local villagers. Nonetheless, there is still land use conflict in Aijia Village, yet it is not the same as the conflict in most villages in the southern mountain area.

The village is surrounded by many scenic spots. There are cherries, apricots, peaches, strawberries and nearly a hundred kinds of other fruits planted in the village. It takes advantages of the beautiful surrounding scenery of mountains and rivers to attract the people living in the city to pick, and set up farmhouse to meet the dining need. This development model is truly a mode of fruit trees-based farming development. Unlike most of the agricultural ecological gardens with affiliated functions like entertainment and science polarization, it also has no construction of a series of artificial landscapes and recreational facilities, which solves the problem of the development of sightseeing agriculture in most villages that are limited by no construction land.

With the merit of ecological environment, modern agriculture attracts a large number of tourists, while the garbage discarded by them has brought a negative impact on the local ecological environment. Besides, as a better development village, yet there are still labor problems of young people flowing out to the city. Most of the agricultural labor forces are middle-aged and the elder, and the aging of the labor force exerts a bad influence on the modernization of traditional agriculture. There is a multivariate game among the stakeholders in Aijia Village (Figure 5).

\subsection{Central Government}

The central government has attached great importance to the issue of agriculture, rural areas and farmers, and always insisted on supporting the agricultural development and exploring its direction of \development. Aijia Village was awarded as the national eco-tourism village, reflecting the support of the central government on its mode of development. The government also builds it into a typical village that guides other villages in agricultural protection and development. 


\subsection{Local Government}

In 2002, the implementation of the "one built and three changes" (building a biogas digester and changing toilet, corral and kitchen) project by Shandong Province for the first time to make the villagers access to "eco-construction". The villagers of Aijia Village who benefited from this project have a view of the development opportunity brought about by the "ecological construction" and find a proper way of local development.

"The government policy gave the opportunity to our village. In fact, all villages have the opportunity to develop, but our village first reached the doorway of development. Do not just wait for the government to help, you should explore your resolution with the help of the government." (villagers from Aijia village).

\subsection{Local Villagers}

Changing of planting from grains and vegetables to fruit trees, Aijia village achieved a considerable income. Thus the planting area of fruit trees like cherry trees has become larger and larger. The once barren hills are now covered with fruit trees to accomplish a reasonable use of land. Moreover, even the courtyards in villagers' houses and the village roads are planted cherry trees if possible, and has formed a unique agricultural landscape. The reputation of the state-level eco-village outside Aijia Village has a strong appeal to the tourists and wealth. Even so, the demographic structure of villagers are mainly middle-aged and the elder and their relative wealth is far from enough according to young people, which leads to significant problems in age structure. Aging problems in Aijia Village are bound to affect the future development of agricultural landscape.

"We are almost the richest village around the neighborhood, but how much money can we earn when most of the people in the village relying on farming? Now cherry trees are planted mainly by the older, who know nothing about the Internet and can only depend on farming to make a living. How can you expect young people to do that kind of business?" (villagers from Aijia village)

\subsection{Tourists}

To discuss the agricultural landscape of Aijia Village, it is necessary to regard the tourists as stakeholders when making an analysis. In this system, the interests of tourists are leisure, sightseeing and experiencing. On the one hand, visitors want to experience the real fun of leisure agriculture. On the other hand, it will put forward some requirements for the local infrastructure and other things. The arrival of tourists plays a positive rule in the development and promotion of local agricultural landscape, which is beneficial for the improvement of local villagers' income. While at the same time, some bad-mannered tourists will bring environmental pollution to the villages.

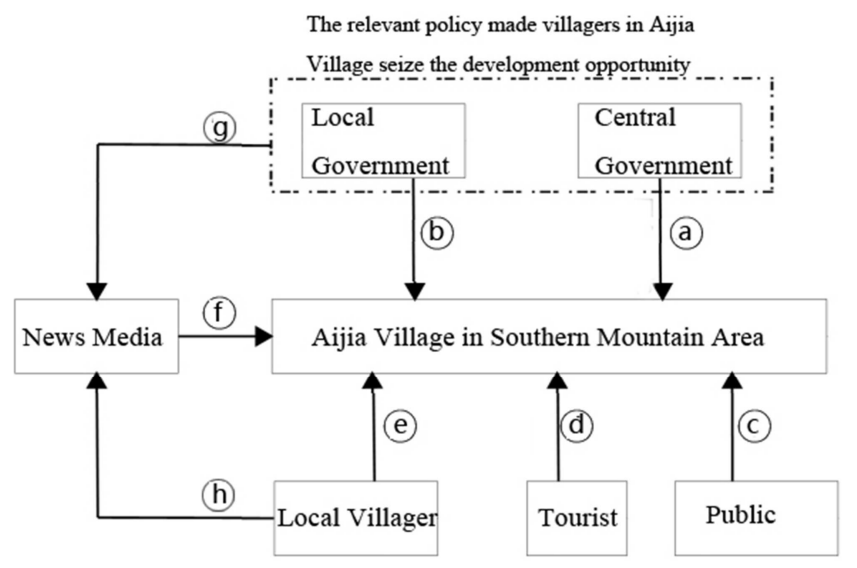

Figure 5. The relationship of gaming among stakeholders in Aijia Village.

a. awarded as a state-level eco-tourism village

b. the plan of enriching the people through ecological development

c. paying attention to ecological environment

d. pollution brought about by the leisure agriculture experience

e. the development of cherry picking industry bringing about a considerable income

f. the publicity and the arousing of attention

g. creating a typical example

h. providing a publicity platform

\section{Conclusion and Prospect}

In recent years, the development of agricultural tourism projects and the citizens' longing for natural scenery provide an essential opportunity for the combination of agriculture and tourism. In the process of agricultural landscape evolution, the influence of social-economy, policy mechanisms, natural environment and various other effects have led to the enactment of returning the cultivated land to forests and developing tourism agriculture, which has become the guidance policy. Consequently, it has resulted in the transformation of land use and spatial mode. Agricultural landscape is an important foundation for urban ecological security in urban fringe areas, and it is also a guarantee for the survival of local villagers. However, in the course of urban development, the game among stakeholders affects the distribution of population and industry. The goal of the government lied in ecological restoration, which to some extent affected the interests of the local villagers and the village collective, giving rise to the conflict of land use between people and the government. In this case, it is of great importance to support and explore the value of agricultural landscape. We should boost the formation of the "pastoral complex" system as much as possible, exert the advantages of natural resources and ecosystem and reach a common mode of protection and the development with villagers on the premise of protecting local ecological environment. The advantage of agricultural landscape not only rests in its production function, but also brings some ecological benefits to the local environment. Considering the development policy of leisure agriculture in China, it is undoubted that the combination of production and landscape will be the point of breakthrough to solve the land use conflict in southern mountain area. 
However, in the view of landscape ecology, the driving forces of the evolution of agricultural landscape spatial mode are complex and multidimensional. As a consequence, only taking the delineation of agricultural land area into consideration is far from enough. We should make a full analysis of the diversity of stakeholders and ensure that the demands of the core stakeholders will be reasonably expressed. We should integrate the development of agriculture and forestry that belonging to primary industry into the tertiary industry, so as to carry out a comprehensive planning during the process of land use evolution to ensure an appropriate spatial pattern of agricultural landscape in the future, so that the value of agricultural landscape functions can be achieved in an all-round way.

\section{References}

[1] Huang Baorong, Zhang Huizhi, Wang Xuezhi. The Impact of Urban Expansion on Natural and Agricultural Landscape of Beijing's Urban-Rural Fringe-Taking Three Towns of Changping District as an Example. [J]. Acta Ecologica Sinica, 2014, 34(22): 6756-6766.

[2] Mi Manning, Zhang Zhenxing, Li Wei. A Study on the Diversity and Development of Domestic Productive Landscape [J]. Ecological Economy 2015, 5: 196-199.

[3] The Southern Provincial Capital of the Ecological Economic
Zone of Scientific Development Expert Group, Gao Huanxi etc. Suggestions on Actively Promoting the Scientific Development of the Ecological Economic Zone in the Southern Provincial Capital (1) [J]. Journal of Shandong Academy of Governance. 2013, 4: 1-8.

[4] Wang Yanglin, Han Dang. Ecological Planning and Design of Agricultural Landscape [J]. Chinese Journal of Applied Ecology. 2000, 2:265-269.

[5] Xie Hualin, Liu Liming, Zhao Yingwei. Studies on the Indicator System of Rural Landscape Evaluation and Evaluating Method [J]. Research of Agricultural Modernization. 2003, 24(2): 95-102.

[6] Shen Mingrui, Zhang Jingxiang. China's Rural Transformation and Revival in the Context of New Urbanization [J]. City Planning Review. 2015(01): 42-47.

[7] Hu Ruiyi, Chen Dongtian, Yu Caiyun, Zhang Ying. Research on Design of Rural Landscape on Low-cost Concept [J]. Shandong Forestry Science and Technology. 2017(08).

[8] Liu Zhihao, Jin Qiming. Study on the Types of Rural Cultural Landscape and Its Evolution [J]. Journal of Nanjing Normal University (Natural Science). 1999, 22(4): 121-128.

[9] Han Yue, Tian Dafang. Construction of Evaluation Index System of Rural Tourism Landscape Attraction [J]. Shanxi Architecture. 2017(01).

[10] Shao Juehan, Liu Binyi. Analyzing the Visual Perception of Rural Landscape [J]. Chinese Landscape Agriculture. 2016(09). 